\title{
The effect of maternity nursing logbook on internship students' skills at woman's health hospital, Assiut Governorate
}

\author{
Ghadah Abdelrahman Mahmoud*1, Ayat Masoud Omar ${ }^{2}$ \\ ${ }^{1}$ Department of Gynecological Nursing and Reproductive Health, Faculty of Nursing, Assiut University, Assiut, Egypt \\ ${ }^{2}$ Department of Maternity and Neonatal Health Nursing, Faculty of Nursing, Fayoum University, Fayoum, Egypt
}

Received: December 18, 2017

Accepted: March 19, 2018

Online Published: May 28, 2018

DOI: $10.5430 /$ jnep.v8n10p130

URL: https://doi.org/10.5430/jnep.v8n10p130

\begin{abstract}
Background and objective: Practical skills in Maternity Nursing are complex actions containing movement abilities, caring intentions, theoretical and practical skills, ethical and moral deliberation. This study aimed to assess the effect of Maternity Nursing logbook on cognitive and practical skills of internship students.

Methods: Quasi-experimental research was carried out in this study. 112 internship students of Faculty of Nursing, Assiut University who were enrolled for Maternity training course around one year by using logbook. Setting: The study was done at the Woman's Health Hospital, Assiut University from beginning of September 2015 to the end August 2016 (internship Training year).

Results: The total score of internship nursing student's cognitive and practical skills revealed that the vast majority of them $(98 \%)$ had satisfactory knowledge and practical skills in post training with significant difference between pre and post training of the internship nursing students.

Conclusions: The using of logbook was associated with increased clinical, cognitive with highly significant difference between pre and post training of the internship nursing students. Recommendations: Implementation of logbook in undergraduate and postgraduate clinical education for all clinical courses.
\end{abstract}

Key Words: Logbook, Cognitive skills, Practical skills, Maternity nursing

\section{INTRODUCTION}

Practical skills are the main part of professional training that has a core role in nursing education. They focus on training competent students in all dimensions of knowledge, skills, and professional attitude. ${ }^{[1]}$ In clinical training students, it can be found that the opportunity to construct their professional identity and to improve their psychomotor skills is very big. ${ }^{[2]}$
The nursing student's responsibility is not clear in clinical field training and they are interested to be aware of objectives of clinical course and providing a clear evaluation method about their responsibility at the first day of clinical field training. Internship program is a requirement for a Bachelor of Science in nursing successful completion of junior year of a baccalaureate .Students must fulfill all prerequisite and co requisite course work for the internship before the first

*Correspondence: Ghadah Abdelrahman Mahmoud; Email: Ghadah.mahfouz@aun.edu.com; Address: Department Gynecological Nursing and Reproductive Health, Faculty of Nursing, Assiut University, Assiut, Egypt. 
day of training to allow students to gain experience in the clinical specialty setting. The primary focus is educational assisting the nursing students to prepare them for a position as a graduate nurse. ${ }^{[3]}$

Functional nature of the nursing profession led to efforts by the researchers for change and improvement in clinical training. They should be considered about the existing problem of nursing clinical education. ${ }^{[4]}$ To save the lives of patients and improve their health, learning of health care practices is essential for both students and teachers. They have expressed that a developed evaluating system is the most important factor in efficiency of clinical education. They even reported that clinical evaluation of students during clinical training is the most effective factor to match the clinical and theoretical nursing education.

More over recently with fast and serious changes of assessing methods in nursing education, new approaches with optimal impact have been developed, mostly focusing on clinical proficiencies. ${ }^{[5]}$ One of these methods is providing written Logbook at training in clinical area that firstly, it can help the students learn better and provide them with an opportunity to strengthen nursing skills. Also, it applies their knowledge in various clinical practices and demonstrate competency in practical skill and procedure. Logbook is a requirement for validating the procedural experience at the advanced training level and reduces the repetition. It allows the learner to record his/her learning practices. So lastly log book is a proper tool for continuous assessment, ongoing interaction between instructor and student and provides a feedback loop for the evaluation of learning activities. ${ }^{[4]}$

A significant part of the nursing education as well as maternity nursing depends on clinical training that is considering the central and basic part of professional training. So, it is indispensable to be precisely assessed by using effective and efficient assessment tool to improve its quality. ${ }^{[6]}$ Numerous experiences are reported by universities on the effectiveness of logbook as assessment tools for evaluating maternity nursing students experiences and other medical educations areas and prevent student errors and confusion in clinical field by sharing standards in clinical education. Students referred to $\log$ book as they abled to manage time and careful planning to have a more effective clinical field. Later findings reported that logbook assessment facilitates effective audit documented learning process. ${ }^{[7]}$

\subsection{Significance of the study}

Nearly, $50 \%$ of the nursing education is spent in the clinical field to achieve measurable changes in students' competencies in clinical care field. ${ }^{[8]}$ Previous studies reported that Published by Sciedu Press there are problems in clinical training evaluation, especially in educational measurement that need the implementation of modern and appropriate methods of clinical evaluation. There is not yet any report available on the implementation of logbook method in our nursing faculties and there is no specific method has been used for evaluating internship students previously; Thus, in line with their duty for finding a way to help the learners achieve optimal performance, the researchers prepared and designed logbook that to provide a guideline and list of major skills/procedures to ensure the achievement of clinical objectives of maternity nursing for internship nursing students of Faculty of Nursing, Assiut University during the internship training period and facilitate the follow up progress of them throughout internship training round at Woman's Health Hospital.

\subsection{Aim of the study}

The aim of the study was to assess the effect of Maternity Nursing Logbook on cognitive and practical skills of Internship Students at Women's Health Hospital, Assiut Governorate.

\section{SubJECT AND METHOdS}

\subsection{Research design}

Quasi-experimental research (pre and posttest) was carried out in this study.

\subsection{Setting}

The study was done at the women's health hospital, Assiut University. The clinical training areas involved the following: (Antenatal ward, Emergency Labour unit, postnatal unit and Intensive Care Unit). The study was conducted from beginning of September 2015 to the end August 2016 (internship training year).

\subsection{Sampling}

Simple random sample was used in this study. The sample was calculated by using Epi-Info Statistical Package, version 3.3 with power $80 \%$, a value of 2.5 is chosen at the acceptable limit of precision (D) at 95\% confidence level (CI) With expected prevalence $10 \%$ which determining the number of internship students in preclinical studies, worst acceptable $25 \%$. Accordingly, sample size was estimated to be $112+$, $10 \%$ of individuals to guard against non-despondence rate.

\subsection{Hypotheses}

Internship nursing students who will receive training course will have high cognitive and practical skills' scores regarding all training guidelines/procedures reported in logbook in the post-training than in pre-training. 


\subsection{Tool}

A log book was used in this study which was designed by the researcher and included the following parts:

Part 1: Attendance record which included the following:

(1) Demographic data: student's name, age, residence, year of graduation and unit of training.

(2) Schedule of training: date, clinical training unit, time in/out and signature of head nurse.

Part 2: Internship student's performance checklist reported by logbook included the following procedures:

(1) Basic nursing care checklist (6 items);

(2) Abdominal examination \& fetal heart rate evaluation (11 items);

(3) Partogram (10 items);

(4) Intrapartum electronic fetal monitoring (17 items);

(5) Management of oxytocin infusion (13 items);

(6) Management of the fourth stage of labor (17 items);

(7) Immediate care of the newborn (24 items);

(8) Fundus and lochia assessment (19 item);

(9) Pitting edema assessment (13 items).

Scoring system was made using three point of rating scale for measuring the level of skill's achievement:

- Satisfactory $(>60 \%)$,

- Unsatisfactory $(<60 \%)$,

- Not applicable $(0.00 \%)$.

\subsection{Methods}

An official permission was obtained from the Scientific Research Ethics Committee at the Faculty of Nursing; Assiut University directed to the managers of Women's Health Hospital, Assiut University.

The study was conducted through three phases:

1) Preparatory phase: In this phase, Maternity Nursing training course and the logbook were developed based on the review of related Maternity Nursing clinical procedures. Time table of the training course was designed during this phase to be conducted through two sessions per day /a week (1st week of the training round), the session duration was around two hrs. Half hour for revising the topic and one and half hour for demonstration. The training course continued for six weeks and the last week for post training evaluation (total 8 weeks for each group). Every two months a group of internship students was changed.

2) Implementation phase: The participating students (112) were divided into focused small groups 12 groups, 9 for each. The researchers interviewed the assigned small focused group ( $\mathrm{n}=9$ students) to explain the nature of the study and illustrate the logbook content (goal, guidelines /skills /procedures). Then the pre-training test was done for all the internship students before conducting the course. The designed course of training was implemented through two sessions per day/a week (1st week of the training round) the session duration was around two hrs. Half hour for presentation the topic and one and half hours for demonstration. Different teaching methods were used such as figures and models by the researchers, in addition to the learning guide (logbook) which is given to each student at the end of the sessions containing a sufficient knowledge about the clinical procedure. The training course continued for six weeks for conducting the training on the practical skills applications and the last week for post training skill's evaluation (total 8 weeks for each group). Every two months a group of internship students was changed.

3) Evaluation phase: At the last week of training course, the internship students were evaluated by using the logbook checklist after completion the training course at women's health hospital training areas (that lasting for 8 weeks). Evaluation of students was done by the researchers all the time during training course with preceptor's assistance. Then the researcher completed the checklist based on student's performance during post training period.

\subsection{The content validity}

Testing validity was done for reassuring clarifications of the tools by a panel of three experts in the specialty of Obstetrics \& Gynecological Nursing.

\subsection{Pilot study}

It was carried out on $10 \%$ of the studied women to test feasibility of the tools and the time needed for applying it. The necessary modifications were done to be consistent with the study.

\subsection{Field work}

The study started at the beginning of September 2015 to the end August 2016.

\subsection{Ethical considerations}

The study protocol was approved by pertinent research and ethical committees. Informed consent was taken from every student before inclusion in the study. Participants were assured that all data are highly confidential. Data was only available to the researchers and the participants. 


\subsection{Statistical analysis}

The data were tested for normality using the AndersonDarling test and for homogeneity variances prior to further statistical analysis. Categorical variables were described by number and percent $(\mathrm{N}, \%)$, where continuous variables described by mean and standard deviation (Mean, SD). Chisquare test and fisher exact test used to compare between categorical variables. A two-tailed $p<.05$ was considered statistically significant. All analyses were performed with the IBM SPSS 20.0 software.

\section{RESULTS}

Table 1 shows that the mean age of internship nursing students was $22.7 \pm 0.49$ years. The majority of them $(89.3 \%)$ were living in urban areas. As regards the area of training in Woman's Health Hospital, nearly one third of them $(32.1 \%)$ received their training at Antenatal inpatient ward.

As regard the basic nursing care which was reported in learning guide, there is statistical significant difference between pre and post training of the internship nursing students $(p<$
$.01)$. These findings explored in Table 2.

Table 1. Personal characteristics of internship nursing students $(\mathrm{n}=112)$

\begin{tabular}{lll}
\hline Personal data & $\mathbf{n}$ & \% \\
\hline Age & $21-23$ & \\
$\quad$ Range & $22.71 \pm 0.49$ & \\
Mean \pm SD & & \\
Residence & 100 & 89.3 \\
Urban & 12 & 10.7 \\
Rural & & \\
Area of training & 36 & 32.1 \\
Antenatal ward & 6 & 5.4 \\
Emergency unit & 13 & 11.6 \\
Intensive Care Unit & 20 & 17.9 \\
Outpatient Clinic & 29 & 25.9 \\
Postnatal ward & 8 & 7.1 \\
Reception unit & & \\
Year of graduation & 112 & 100.0 \\
2015 & & \\
\hline
\end{tabular}

Table 2. Internship nursing students' skills as regards basic nursing care

\begin{tabular}{|c|c|c|c|c|c|}
\hline \multirow{3}{*}{ Basic Nursing Care reported in logbook: } & \multicolumn{4}{|c|}{ Student's Skills } & \multirow{3}{*}{$p$} \\
\hline & \multicolumn{2}{|c|}{$\begin{array}{l}\text { Pre training } \\
(\mathrm{n}=112)\end{array}$} & \multicolumn{2}{|c|}{$\begin{array}{l}\text { Post training } \\
(n=112)\end{array}$} & \\
\hline & $\mathbf{n}$ & $\%$ & n & $\%$ & \\
\hline Measuring vital signs (Pulse, respiration, blood pressure, temperature) & 86 & 76.8 & 112 & 100.0 & $<.001 * *$ \\
\hline Patient's hygiene & 86 & 76.8 & 112 & 100.0 & $<.001 * *$ \\
\hline Measuring weight and height & 75 & 67.0 & 112 & 100.0 & $<.001^{* *}$ \\
\hline Testing blood sugar by glucometer & 88 & 78.6 & 112 & 100.0 & $<.001^{* *}$ \\
\hline Administration of Medications & 86 & 76.8 & 111 & 99.1 & $<.001^{* *}$ \\
\hline Following aseptic technique in each procedure & 82 & 73.2 & 112 & 100.0 & $<.001^{* *}$ \\
\hline
\end{tabular}

Another procedure is an abdominal examination and auscultation of fetal heart rate identifies in Table 3 that there is statistical significant difference between pre and post training of the internship nursing students $(p<.01)$. Partogram application also explores that there is statistical significant difference between pre and post training of the internship nursing students $(p<.01)$.

Table 4 assesses the total score of internship nursing student's cognitive and practical skills. It revealed that the vast majority of them (98\%) had satisfactory knowledge and practical skills in post training with statistical significant difference between pre and post training of the internship nursing students $(p<.01)$.

Figure 1 shows that nearly one third of internship nursing Published by Sciedu Press students $(29.5 \%)$ attended training courses in Obstetrics \& Gynecological Nursing with statistical significant difference between pre and post training of the internship nursing students as regard the attendance of in Obstetrics and Gynecological Nursing $(p<.01)$.

Figure 2 explores that the highest percentage of Internship Student's Grades was very good $(61.6 \%)$ with statistical significant difference between pre and post training of them $(p$ $<.01)$.

The last finding explores that gaining knowledge, practical and communication's skills is the highest percentage about the benefits gained from the training in health setting reported by the students followed by raising their self-confidence $(43.8 \%$ \& $25 \%)$ respectively (see Table 5). 
Table 3. Internship nursing students' skills as regards abdominal examination \& fetal heart rate evaluation

\begin{tabular}{|c|c|c|c|c|c|}
\hline \multirow{3}{*}{$\begin{array}{l}\text { Abdominal examination \& fetal heart rate evaluation } \\
\text { reported in logbook: }\end{array}$} & \multicolumn{4}{|c|}{ Time } & \multirow{3}{*}{$p$} \\
\hline & \multicolumn{2}{|c|}{$\begin{array}{l}\text { Pre training } \\
(\mathrm{n}=112)\end{array}$} & \multicolumn{2}{|c|}{$\begin{array}{l}\text { Post training } \\
(\mathrm{n}=112)\end{array}$} & \\
\hline & $\mathbf{n}$ & $\%$ & $\mathbf{n}$ & $\%$ & \\
\hline Inspect the abdomen for scars, hair distribution, skin pigmentation, shape \& enlargement. & 82 & 73.2 & 100 & 89.3 & $.003 * *$ \\
\hline Measure fundal height. & 78 & 69.6 & 104 & 92.9 & $<.001^{* *}$ \\
\hline Carry out fundal palpation to locate the part of the fetus occupying it. & 65 & 58.0 & 103 & 92.0 & $<.001^{* *}$ \\
\hline Palpate the sides of uterus to locates the fetal back \& limbs "lateral grip". & 84 & 75.0 & 96 & 85.7 & .064 \\
\hline Palpate the lower part of the uterus to locate part of the fetus occupying it "pelvic grip". & 75 & 67.0 & 101 & 90.2 & $<.001^{* *}$ \\
\hline Determine engagement of the presenting part by using “pawlik’s grip”. & 80 & 71.4 & 106 & 94.6 & $<.001^{* *}$ \\
\hline Listen to the fetal heart rate. & 64 & 57.1 & 97 & 66.6 & .184 \\
\hline Drape the exposed abdomen. & 82 & 73.2 & 110 & 98.2 & $<.001^{* *}$ \\
\hline Remove gloves by turning them inside out. & 90 & 80.4 & 110 & 98.2 & $<.001^{* *}$ \\
\hline Help the woman off the examination table. & 86 & 76.8 & 104 & 92.9 & $.001 * *$ \\
\hline Share your findings with the woman. & 88 & 78.6 & 104 & 92.9 & $.004 * *$ \\
\hline
\end{tabular}

** $p<.01$

Table 4. Total skills' scores of internship nursing students as regard all training procedures

\begin{tabular}{|c|c|c|c|c|c|}
\hline & \multicolumn{4}{|c|}{ Time } & \multirow{3}{*}{$p$} \\
\hline & \multicolumn{2}{|c|}{ Pre training $(n=112)$} & \multicolumn{2}{|c|}{ Post training $(n=112)$} & \\
\hline & $\mathbf{n}$ & $\%$ & $\mathbf{n}$ & $\%$ & \\
\hline \multicolumn{6}{|l|}{ The main training procedures in Logbook } \\
\hline Basic nursing care & 88 & 78.6 & 112 & 100.0 & $<.001^{* *}$ \\
\hline Abdominal examination \& fetal heart rate evaluation & 92 & 82.1 & 110 & 98.2 & $<.001 * *$ \\
\hline The partogram & 60 & 53.6 & 107 & 95.5 & $<.001^{* *}$ \\
\hline Intrapartum electronic fetal monitoring & 78 & 69.6 & 112 & 100.0 & $<.001^{* *}$ \\
\hline Management of oxytocin infusion & 75 & 67.0 & 112 & 100.0 & $<.001^{* *}$ \\
\hline Management of the fourth stage of labor & 35 & 31.3 & 102 & 91.1 & $<.001^{* *}$ \\
\hline Immediate care of the newborn & 31 & 27.7 & 102 & 91.1 & $<.001^{* *}$ \\
\hline Fundus and lochia assessment & 29 & 25.9 & 102 & 91.1 & $<.001^{* *}$ \\
\hline Pitting edema assessment & 36 & 32.1 & 108 & 96.4 & $<.001^{* *}$ \\
\hline \multicolumn{6}{|l|}{ Score of Student's skills } \\
\hline Satisfactory (60\%) & 63 & 56.3 & 110 & 98.2 & $<.001^{* *}$ \\
\hline Unsatisfactory & 49 & 43.8 & 2 & 1.8 & \\
\hline
\end{tabular}

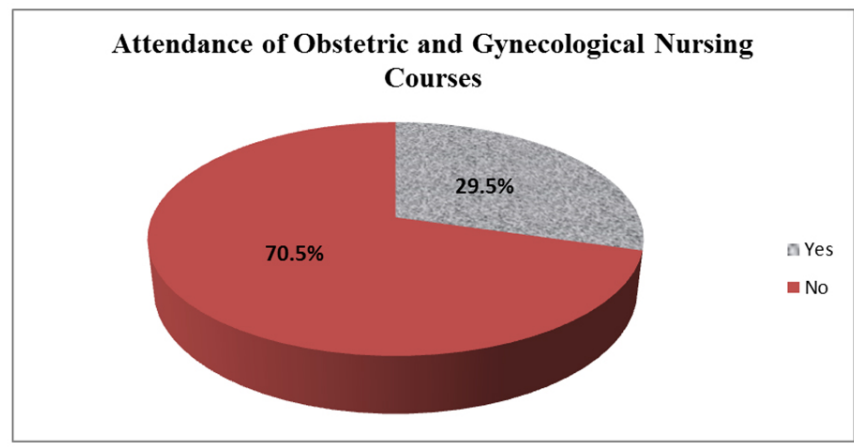

Figure 1. Attendance of obstetric and gynecological nursing courses 


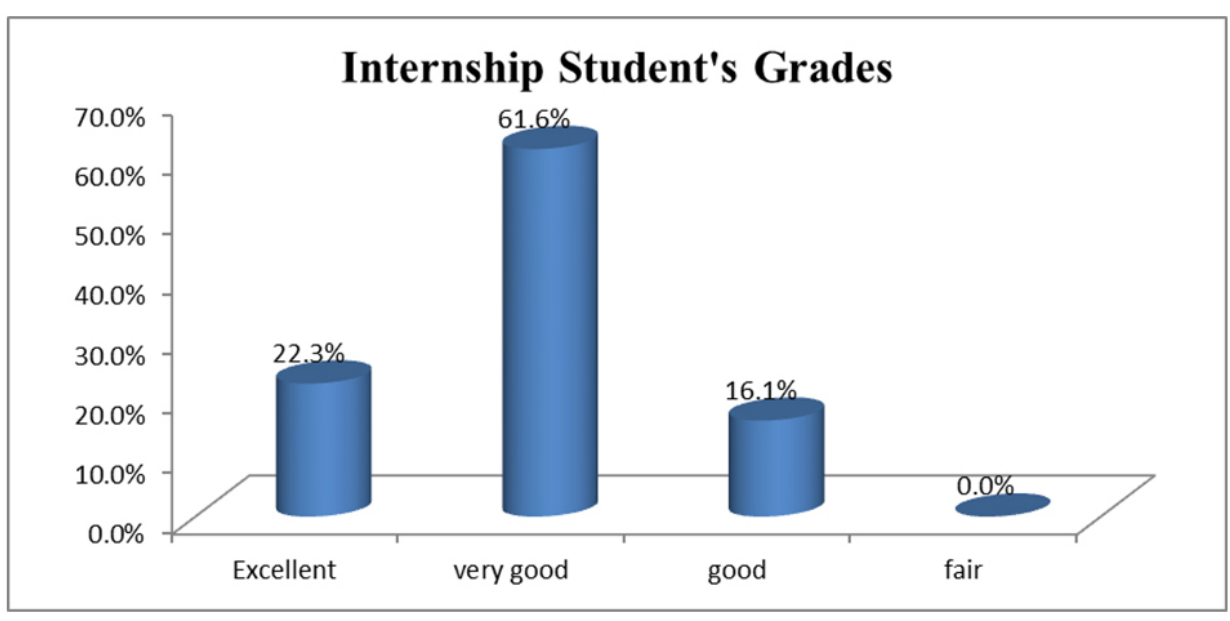

Figure 2. Internship student's grades

Table 5. Benefits of clinical training in Health setting reported by internships nursing students

\begin{tabular}{lll}
\hline Benefits from clinical training in Health setting & n & \% \\
\hline Gaining cognitive, practical and communications skills & 49 & 43.8 \\
Acquiring new clinical experiences & 22 & 19.6 \\
Raising students Self confidence & 28 & 25 \\
Enhancing the concept of patients centered Care & 19 & 17 \\
Training on using Health information System & 14 & 12.5 \\
Developing Leadership Skills & 10 & 8.9 \\
\hline
\end{tabular}

\section{Discussion}

Evaluation is the most sufficient approach to improve the quality of education. In order to reach this goal, there have been many tools that one of them is logbook. Today, logbook application has found prevalent use in medical and nursing education and is currently being used in clinical assessment. $^{[7]}$

The present study revealed Sociodemographic characteristics of internship nursing students. In the same line of these findings of Torabi (2013) ${ }^{[9]}$ who studied the effect of logbook as a study guide in dentistry training in Iran showed that the students' mean age was 23 years. In partial agreement with these findings of Mahboubeh et al. (2011) ${ }^{[10]}$ who studied the Effect of Logbook on Nursing and Midwifery Students Clinical Skills in Sari and reported that the students' mean age of the students was $24.18 \pm 2.012$ and the highest age was 24 years. The variation in age groups may relate to the differences of gender age groups and levels of education between both studies. As revealed in the present study regarding the basic nursing care which was reported in learning guide, there is statistical significant difference between pre and post training of the internship nursing students.

In agreement with this finding, Mahboubeh et al. (2011) ${ }^{[10]}$ Published by Sciedu Press found that the mean score of pre-test and post-test general skills were showed significant differences between both groups. The differentiation of between the present studies and others may refer to the variation in the sample size, type and the places of conducting the studies.

Saber and Firouzi (2008) ${ }^{[11]}$ who studied the logbook effect on clinical learning of interns in Internal Ward Rotation in Shiraz University of Medical Sciences in Iran, reported that the students believed that the logbook was successful in objective orientation of learning experiences, documenting these experiences, and reflection on experiences but it seems that no improvement on students-teacher interaction happened.

A statistical significant difference revealed between pre and post training of the internship nursing students regarding procedures included in maternity logbook as abdominal examination, auscultation of fetal heart rate, partogram application, management of labour, newborn care and fundal and lochia assessment. These findings support the idea that active learning and logbook guideline and reflection is the best way to improve the students' learning. Agreement with this findings study done by Torabi (2013) ${ }^{[9]}$ about the effect of logbook as a study guide in dentistry training in Shiraz University of Medical Sciences in Shiraz, reported that there were a significant difference in the study group and also in the control group when comparing the mean scores of the pre-and post-tests.

Also this was in coherence with Mahboubeh et al. (2011) ${ }^{[10]}$ who reported that the mean scores of pre-test and post-test skills in the experiment (with Logbook) was increased.

As regarding to the total score of internship nursing student's cognitive and practical skills our results revealed that the vast majority of interns had satisfactory knowledge and practical 
skills in post training with statistical significant difference between pre and post training of the internship nursing students.

These findings agreed with Aliresa (2012) ${ }^{[12]}$ who studied the developing a clinical performance logbook for nursing students receiving cardiac care field training in Esfahan and concluded that logbook which can be a valuable tool for assessing the clinical competency of nursing students receiving field training in cardiac care units (CCU). This may be due to the variation in the sample characteristics. Also Raghoeber and Helga (2001) ${ }^{[13]}$ who investigate when and how internship medical student should complete the log book among internship medical student at faculty of medical science, university of Groningen, the Netherlands and concluded that the completing of the logbook during internship with supervision was the optimal condition to obtain accurate information and this ensure the effectiveness of logbook.

In partial agreement of this findings Lotfi et al. (2014) ${ }^{[14]}$ who studied the effect of Using Logbook on Nursing Students' Learning in Iran reported that the mean score of the experiment group in ICU ward in both cognitive and psychomotor domains was significantly higher than that of the control group. Although the experiment group's mean score in both domains in CCU ward increased compared to the control group but the difference was not significant. It may be due to the variation in the sample size, type and the places of conducting the studies.

On the other hand, Torabi's (2013) ${ }^{[9]}$ findings were in agreement with our findings and documented that the comparison of self-ratings of the logbook's objective revealed that there were significant differences between the experimental and control groups in some areas and students who did not receive the logbook had a lower rating in their self-assessments in some areas.

Our findings identified that there was highly significant difference between pre and post training of the internship students. This might be a development of the ongoing follow-up and contact between students and supervisor. Hence, it is interpreted that using logbook was effective in increasing practical and cognitive skills of internship. Agreement with these findings.

Ghadam (2014) ${ }^{[15]}$ who reported that following the intervention of log book among twenty four undergraduate physiotherapy student at Hormozgan University of Medical science, faculty of rehabilitation demonstrated descriptively that among 23 analyzed educational items, the students' most satisfactions by using log book obtained from the education of physiotherapy recording manner, documentation of experi- ence and their possible comparison in different semesters, improvement of self-evaluation spirit, and systematic recording of educational tasks.

Another key finding reported in the present study that gaining knowledge, practical and communication's skills was the highest percentage about the benefits gained from the training in health setting reported by the students followed by raising their self-confidence $(43.8 \% \& 25 \%)$ respectively. These findings congruent with Torabi $(2013)^{[9]}$ who concluded that the finding of their study suggests that logbook plays an important role in attainment of the psychomotor and cognitive domain in fixed courses of dental curriculum. Also, it was evident from Karampourian (2015) ${ }^{[7]}$ who studied the effect of using logbook on emergency medical services student's satisfaction and clinical evaluation, in Hamadan University in Iran of Medical Sciences in 2013 the mean score of students' satisfaction from evaluation by logbook was $2.55 \pm 0.62$, mean score of students' self-evaluation was $2.96 \pm 1.03$. Moreover, Azizi and collogues $(2016)^{[16]}$ who studied the effect of log book design and implementation on students' satisfaction and performance during a nursing internship course in a military psychiatric hospital in Iran and revealed in their findings that although students' scores in log book method were higher than the traditional method, with a significant difference between them also the satisfaction from traditional method was more than the log book method. Therefore, a need for further studies and revisions is necessary in other training centers.

In consistent with our findings, Khorashadizadeh (2012) ${ }^{[17]}$ studied students perception about logbooks: advantages, limitation and recommendation among undergraduate nursing students in in the neonatal intensive care unit and pediatrics ward of a regional hospital in Bojnord, Iran and concluded that the students found the logbook to be an invalid assessment tool because some records in logbooks may be fake and the students may not have performed those tasks. In parallel with this study findings, Taylor (2004) ${ }^{[18]}$ studied the procedural skills quality assurance among Australasian College for Emergency Medicine in fellows and trainees in Australia and documented that current logbooks are only a record of work that students carried out, and not of the outcome of their performance. Therefore, logbooks do not adequately prepare trainees for a lifetime of effective audit and self-learning. This may be due to difference in the sample size type and the places of conducting the studies.

\section{Limitation of the study}

A limitation of this study was applied in a single university, and single course might limit its generalization to different settings. 


\section{Conclusions}

The using of logbook was associated with increased clinical and cognitive skills with significant difference between pre and post training of the internship nursing students as regards the total scores of Basic nursing and Obstetric procedures reported in logbook.

\section{Recommendations}

- Further studies is necessary in other training nursing course.

- Implementation of logbook in undergraduate and postgraduate clinical education for all clinical courses.
- Insert logbook as a method of evaluation of internships students during internship training course in the nursing bachelor program.

\section{ACKNOWLedgements}

The researchers wish to thanks all the internship nursing students for their participation in this study. Other grateful thanks for nursing preceptors who aiding in conducting the study.

\section{CONFlicts of InTERest Disclosure}

The authors declare that there is no conflict of interest.

\section{REFERENCES}

[1] Yousefy A, Shayan S, Mosavi A. Developing a clinical performance logbook for nursing students receiving cardiac care field training. J Educ Health Promot. 2012; 1(7).

[2] Wallace J. Nursing Student Work-Study Internship Program: An Academic Partnership. J Nurs Educ. 2016; 55(6): 357-9. PMid:27224467 https://doi.org/10.3928/01484834-20160516-11

[3] Mohammadi A, Khaghanizadeh M, Ebadi A, et al. Log book: a method of evaluating education and feedback strategy in nursing. Iranian Journal of Educational Strategies. 2010; 3(1): 41-45.

[4] Gustafsson M, Kullén Engström A, Ohlsson U, et al. Nurse teacher models in clinical education from the perspective of student nurses A mixed method study. Nurse Education Today. 2015; 13(6).

[5] Göran D, Georgios T, Hans H. Continuous self-assessment during 1 year in paediatric dentistry. European Journal of Paediatric Dentistry. $2014 ; 15(3)$

[6] Mohebi Z, Najafi M, Mgharaei M. Clinical learning Nursing and Midwifery College; Medical surgical nursing logbook. Shiraz University of Medical Science. 2010; 3(7).

[7] Karampourian A, Khatibian M, Jahangir IK, et al. The effect of using Logbook on Emergency Medical Students' satisfaction and clinical evaluation, in Hamadan University of Medical Sciences. Pajouhan Scientifi Journal. 2015; 13(2): 50-5.

[8] Marzieh A, Negin M, Mohsen A. Clinical Self-Efficacy in Senior Nursing Students: A Mixed-Methods Study Nurs. Midwifery Stud. 2015; 4(3): e29143. PMid:26576443

[9] Torabi K, Bazrafkan L, Sepehri S, et al. The effect of logbook as a study guide in dentistry training. J. Adv Med \& Prof. 2013; 1(3): 81-84.
[10] Mahboubeh Y, MoloudFakhri F. Assessment of the Effect of Log Book on Nursing and Midwifery Students' Clinical Skills. MiddleEast J Sci. Res. 2011; 7(6): 896-902.

[11] Saber M, Saberi M. The Logbook Effect on Clinical Learning of Interns in Internal Ward Rotation in Shiraz University of Medical Sciences. Journal of Medicine Eduction. 2008; 12(3).

[12] Aliresa. The developing a clinical performance logbook for nursing students receiving cardiac care field training in Esfahan. Iranian Nursing Journal. 2012; 13(12): 220-225.

[13] Raghoebar-Krieger H. The objectives-based logbook: a tool for evaluation of medical education. College of Groningen. Medical Teacher. 2001; 23: 315 .

[14] Lotfi M, Fariborz R, Mojgan 1. The Effect of Using Logbook on Nursing Students' Learning. Iranian Journal of Medical Education. 2014

[15] Talebi GA, Ghaderi F, Oskouei AE. Using Logbook in Clinical Education of Physiotherapy Students. Development Strategies in Medical Education. 2014; 1(2): 51-58.

[16] Azizi M, Barati H, Khamse F, et al. The effect of log book design and implementation on students' satisfaction and performance during a nursing internship course in a military psychiatric hospital, Ebnesina IRIAF Health Administration. 2016; 18(2): 55-60.

[17] Khorashadizadeh F, Alavinia S. Students perception about Logbooks: advantages, limitation and recommendation a qualitative study. Iranian Journal of Medical Education. 2012; 10(8): 66-70.

[18] Taylor DM, Harrison G. Procedural skills quality assurance among Australasian College for Emergency Medicine fellows and trainees. Emerg Med Australas. 2006; 18: 268-75. PMid:16712537 https : //doi.org/10.1111/j.1742-6723.2006.00852.x 